\title{
AS FONTES DE DUARTE PACHECO PEREIRA NO "ESMERALDO DE SITU ORBIS" (*).
}

Ainda que o Esmeraldo de situ orbis de Duarte Pacheco Pereira tenha sido quase unânimemente considerado pelos historiadores da literatura e da cultura portuguêsas como um roteiro da costa de África, a verdade é que esta obra encerra aspectos que nos obrigam a considerá-la como um texto bastante complexo. Surge-nos como uma espécie de síntese de todo um conjunto de obras anteriores relativas aos descobrimentos marítimos.

Duarte Pacheco Pereira refere-se na sua obra a um grande número de acontecimentos históricos, e se bem que sempre com brevidade, fá-lo de uma maneira que lembra as crônicas medievais, e especialmente a Crônica dos feitos de Guiné de Gomes Eanes de Zurara, a única crônica conhecida que relata viagens de descobrimento. Não falta mesmo no Esmeraldo de situ orbis o panegírico do Infante D. Henrique (1), e também o de $\mathrm{D}$. Manuel (2) que reinava no momento em que Duarte $\mathrm{Pa}$ checo Pereira redigia a sua obra. A grandiloqüência, e uma certa mentalidade do conquistador que desprezava muitas vêzes os princípios humanitários, são traços comuns à Crônica dos feitos 'de Guiné e ao Esmeraldo de situ orbis. E' esta a razão porque consideramos a obra de Duarte Pacheco Pereira não sòmente como um roteiro da costa de Africa, mas também como um livro de história que muitos traços ligam às crônicas medievais.

Vemos por outro lado no Esmeraldo de situ orbis capítulos em que Duarte Pacheco Pereira nos fala dos círculos terrestres (3), das coordenadas terrestres (4), da maneira de calcular as

(₹). - Com êste mesmo título publicamos uma versāo muito abreviada dêste estudo: As fontes de Duarte Pacheco Pereira no "Esmeraldo de situ orbis" (Breve' apontamento), in "Publicaciones del Curso Hispano-Português de Orense", 1963.

(1). - Livro I, Capítulo 22.

(2). - Prólogos dos Livros I e IV.

(3). - Livro I, Capítulo 1.

(4). - Moidem. 
latitudes (5), do curso do sol relativamente aos trópicos (6), da declinação (7), das marés e das suas relações com as fases da lua (8). Em conseqüência, o Esmeraldo de situ orbis surgenos também como um livro de cosmografia e um regimento de navegação.

Também as duas cópias do século XVIII que até nós chegaram, a da Biblioteca Pública e Arquivo Distrital de Évora (9), e a da Biblioteca Nacional de Lisboa (10) que afinal não é mais do que uma cópia da anterior (11), exibem 16 vêzes as palavras aqui mapa (12), não contando com as alusões no texto a dois verdadeiros mapas (13). Por esta razão certos historiadores (14), desprezando o fato que a legenda aqui mapa é da inteira responsabilidade do copista do século XVIII e não designa mais do que simples vistas de costa, pensaram que o Esmeraldo de situ orbis não era apenas um roteiro, mas também um atlas.

A obra de Duarte Pacheco é, no entanto, antes de mais nada, um roteiro ao mesmo tempo que um livro de geografia e de cosmografia. E' o próprio Duarte Pacheco Pereira que afirma ser o seu Esmeraldo de situ orbis um livro de cosmografia e marinharia (15).

\footnotetext{
(5). - Livrò I, Capítulo 8.

(6). - Livro I, Capítulo 9.

(7). - Livro I, Capítulo 10.

(8). - Livro I, Capítulos 11 e 12.

(9). - Manuscrito CXV, 1-3.

(10). - Seção de Reservados, Fundo Geral 888; cota antiga: Manuscrito B-17, 7.

(11). - Ver demonstração na nossa obra: "Esmeraldo de situ orbis" de Duarte Pacheco Pereira (Edition critique et conumentée), no prelo.

(12). - Livro I, Capítulo 13; L. I, Cap. 13; L. I, Cap. 14; L. I, Cap. 14; L. I, Cap. 15; L. I, Cap. 16; L. I, Cap. 17; L. I, Cap. 18; L. I, Cap. 18; L. I, Cap. 18; L. I, Cap. 22; I. I, Cap. 28; L. I, Cap. 33; I. II, Cap. 1; L. II, Cap. 10; I. III, Cap. 7.

(13). - Livro I, Capítulo 5; L. I, Cap. 28; L. III, Cap. 7.

(14). - Diogo Barbosa Machado: Biblioteca Lusitana, 2a. edição, Lisboa, 1930, tomo I, p. 722; Luciano Pereira da Silva: Duarte Pacheco Pereira - precursor de Cabral, in História da Colonização Portuguêsa do Brasil, volume I, Pôrto, 1921, págs. 231, 252, ou êste mesmo estudo nas obras Completas de Luciano Pereira da silva, volume II, Lisboa, 1945; Armando Cortesão: Cartografia e Cartógrafos Portuguêses dos séculos XV e XVI (Contribuição para um estudo completo), Lisboa, 1935, volume I, págs. 105-106; Armando Cortesão e Avelino Telxeira da Mota: Portugaliae Monumenta Cartographica, Lisboa, 1960, volume I, pág. 179; A Teixeira da Mota: A evoluçáo da ciência náutica durante os séculos XV-XVI na cartografia portuguêsa da época, edição da Junta de Investigaçōes do UItramar, Lisboa, 1961, pág. 12.

(15). - Livro 1, Prólogo.
} 
Se: a lenda, a historiografia do século XVI - Fernão Lopes de Castanheda (16), João de Barros (17), Gaspar Correia (18), Damião de Góis (19), Jerônimo Osório (20), - e até a poeșia - Luís de Camões nos Lusíadas (21) e outros poetas (22) apresentam Duarte Pacheco Pereira apenas como um chefe militar prestigioso, célebre pelas suas façanhas na Índia, não podemos nem devemos no entanto esquecer que êle foi também um navegador e um técnico de navegação particularmente hábil. Foi a êstes títulos que êle foi encarregado de reconhecer muitos pontos da costa ocidental de Africa (23), de dirigir em 1498 uma expedição secreta para as costas do Brasil (24), de discutir com os castelhanos àcêrca do estabelecimento da fa-

(16). - História do Descobrimento e Conquista da fndia pelos Portuguêses, $3 a$. edição por Pedro de Azevedo, Coimbra, 1924, Livro I, Capítulos 55 $56-58-59-60-62-63-65-66-67-68-69-70$ $71-72-73-74-75-76-77-78-79-80-81-82-$ $83 \longrightarrow 84-85-86-87 \longrightarrow 88-89-91-92-93-94-95-96-97$.

(17).: - Asia, Primeira Década, 4a. edição, revista e prefaciada por Antônio Baião, Coimbra, 1932; ver o Livro VII, Capitulos $2-3-5-6-7$ $8-9-10$ e 11 .

(18). - Lendas da fndia, publicadas sob-a direção de Rodrigo José de Lima Felner, Lisboa, 1858. Tomo I, ver a parte que diz respeito à Armada dos Alboquerques, que passarão à Índia, o anno de 503, Capítulos $1-3$ $5-6-7-9-10-11-12-13-14-15-16-$ $17-18-19-20-21-22-23$. Ver ainda no Tomo I a parte que diz respeito à Armada de Lopo Soares que passou à fndia o ano de 1504, capítulos $2-3-4-5-6$.

(19). - Crônica del-Rei Dom Manuel (Biblioteca de Clássicos Portuguêses, Lisboa, 1909). Ver a Primeira Parte, Capítulos $77-78-80-85-86-$ $87-88-89-90-91-92-96-97-99-100$.

(20). - Histoire de. Portugal, contenant les entreprises, navigations, \& gestes memorables des Portugallois, tant en la conqueste des Indes Orientales par eux descouvertes, qu'ès guerres d'Afrique \& autres exploits, depuis l'an mil quatre cens nonãte six, sous Emmanuel premier du nom. Paris, 1581. (Ver o Liv̀ro III, fôlhas 85-101, e o Livro IV, fôlhas 108-109).

- L'Histoire de Portugal, comprise en deux volumes, contenans infinies choses memorables avenues depuis l'an du Seigneur M. XC. jusques à l'an MDCX sous le regne de vingt Roys. Genève, MDCX. (Ver o volume I, livro 3, págs. 183-240, e livro I, pág. 259).

(21). - Lusíadas; edição da Imprensa Nacional, texto estabelecido por José Maria Rodrigues, Lisboa, 1931; Canto $X$, estâncias 12-25.

(22). - Pedro de Andrade Caminha: Poesias, publicadas pela Academia Real das Scienclas de Lisboa, 1791, pág. 265.

- Jacinto Cordeiro: Prospera e Adversa Fortuna de Duarte Pacheco Pereira. Em Duas Comedias pello Alferes Jacinto Cordeiro. Publicadas em Portugal por Craesbeck em 1630 .

- Miguel Cerqueira Doce: Vitórias de Duarte Pacheco, e de outros capitaens, que com valor, e esforço militarão na India oriental, poema em dez cantos, rimas oitavas, manuscrito redigido em 1631.

- Antonlo Dinys da Cruz e Silva: Odes Pindáricas, Londres, 1820; Ode XIV, págs. 80-85.

(23).: - Esmeraldo de sítu orbis, L. I, Prólogo, L. I, Cap. 5, L. II, Caps. 7, 8, 11. (24) . - L. I, Cap. 2. 
mosa linha dita de Tordesillas (25). Desde 1505 que Duarte Pacheco Pereira dava o grau de meridiano com um êrro de apenas $4 \%$ (26), quando o êrro corrente na época variava entre 7 e $15 \%$. Este progresso foi de tal maneira extraordinário que foi preciso esperar mais de dois séculos (1762) para que o número estabelecido por Duarte Pacheco Pereira começasse a ser utiliżado (27) .

Que obras terá lido êste homem tão complexo? A partir de que fontes elaborou êle a sua obra não menos complexa? Dissemos que o Esmeraldo de situ orbis era um livro de história, uma espécie de crônica. Se encararmos êste aspecto da obra, não encontramos nela mais do que meia dúzia de passos suscetíveis de ser referidos a uma fonte:

\section{1). - O passo do Prólogo do Livro I,}

e êle foi o princípio e causa que os Etiópios, quise bestas em semelhança humana, alienados do culto divino, dispam per tua indústria sua bestialidade, e muita parte dêles à santa fé católica e religião cristã cada dia são trazidos (28),

é sem dúvida a transcrição de um passo da carta de Jerônimo Munzer (Hieronimo Monetario) a D. João II, escrita em

(25). - Pode ver-se o texto integral do Tratado de Tordesillas (7 de junho de 1494) nas seguintes publicações; Alguns documentos do Arquivo Nacional da Tôrre do Tombo àcêrca das navegaçöes e conquistas portuguêsas, publicados por ordem do Govêrno de $\mathrm{S}$. Majestade Fidelissima ao celebrarse a comemoração quadricentenária do descobrimento da América, Lisboa, 1892, págs. 69-80; Anais da Academia Portuguêsa da História, 2a. série, Lisboa, 1946, volume I, págs. 243-254; Crônica de El-Rey Dom João II de Rui de Pina, edição de Alberto Martins de Carvalho, Coimbra, 1950 , págs. $243-257$.

(26). - Esmeraldo de situ orbis, L. I, Cap. 2.

(27). - Manuel Pimentel: A arte de navegar, Lisboa, 1762, págs. 93-94. Ver sôbre o valor do grau de meridiano: Luciano Pereira da Silva, Duarte Pacheco Pereira - precursor de Cabral, in História da Colonização Portuguêsa do Brasil, volume I, Pôrto, 1921, págs. 235-241, ou êste mesmo estudo nas Obras Completas de Luciano Pereira da Silva, volume II, Lisboa, 1945; A. Fontoura da Costa - La lieu marine des Portugais aux XVe-XVIe siè cles, in Boletim da Sociedade de Geografia de Lisboa, 56a. série, n. $0_{5}$ 9-10, setembro-outubro de 1938; A. Fontoura da Costa - A Marininaria dos Descobrimentos, Lisboa, 2a. edição, 1939, págs. 211-216; A. Teixeira da Mota - Bartolomeu Dias e o valor do grau terrestre, in Actas do Congresso Internacional de História dos Descobrimentos, Lisboa, 1961 . volume II.

(28), - No manuscrito-cópia do século XVIII faltam as palavras: per tua in. dústria sua bestialidade. Foi a carta de Munzer que nos permitiu reconstituir o texto. Todos os textos do Esmeraldo de situ orbis citados neste trabalho provêm da nossa edição: "Esmeraldo de situ orbis" de Duarte Pacheco Pereira (Edition critique et commentée), no prelo: 
Nuremberg a 14 de julho de 1493 , e traduzida do latim para português por Mestre Álvaro da Tôrre (29):

os de Ethiopia quasi bestas em semelhança humana alienados do culto divino dispam per tua industria sua bestialidade e uenham a guardar a religiom catholica (30).

Esta carta foi impressa no final da coletânea comumente conhecida por Regimento de Munich. Esta coletânea tem como título Regimento do Estrolabio e do Quadrante - Tractato da Spera do Mundo na edição de Joaquim Bensaude, publicada em Munique em 1914 e que é uma Reproduction facsimilé du seul exemplaire connu appartenant à la Bibliothèque Royale de Munich. Trata-se de uma coletânea em que além do Regimento do Estrolabio e do Quadrante, vemos um texto em língua portuguêsa do Tratado da Esfera de Sacrobosco, e no final a citada carta de. Jerônimo Munzer. Esta coletânea foi imjressa por Hermão de Campos, que segundo Antônio Joaquim Anselmo (31) só teria começado a trabalhar como impressor em Portugal após 1509, data posterior à redação do Esmeraldo de situ orbis (32). Duarte Pacheco Pereira teria pois tomado conhecimento desta carta em data anterior à da sua impressão, a não ser que admitamos, com Otto Hartig, antigo conservador na Biblioteca Real de Munique, que o único exemplar conhecido da célebre coletânea não seja a edição princeps (33). Ain-

(29). - Ver sôbre Ālvaro da Tôrre: Historisches Jahrbuch, Munchen, 1908, págs. 304-337.

(30). - Duarte Leite (História dos Descobrimentos - Coletânea de esparsos, organização, notas e estudo final de Vitorino Magalhães Godinho, volume I, Lísboa, 1959, pág. 105) já se havia apercebido dêste fato. Ver ainda no volume II desta obra o estudo de Vitorino Magalhães Godinho, Duarte Leite e a evolução dos estudos em história dos descobrimentos, pág. 558.

(31). - Bibliografia das obras impressas em Portugal no século XVI, Lisboa, 1926, pág. 116.

(32). - Duarte Pacheco Pereira começou a redação da sua obra pelo mês de agôsto de 1505, abandonando-a inacabada nos primeiros meses de 1508 . Ver sôbre êste assunto a nossa obra, em preparação: L"'Esmeraldo de situ orbls" de Duarte Pacheco Pereira et la littérature portugaise de voyages à l'époque des grandes découvertes.

(33). - Otto Hartig: Historisches Jahrbuch, Munchen, 1908, Bd. 29, Heft 2, pág. 336; ver ainda sôbre êstes assuntos: Joaquim Bensaude - L'astronomie nautique au Portugal à l'époque des grandes découvertes, Berna, 1912, págs. 7-8, 70, 168-174; Joaquim Bensaude - Regimento do Estrolabio e do Quadrante - Tractado da Spera do Mundo, Munich, 1914, Introduction, pág. 8; Luciano Pereira da Silva - Obras Completas, Agência Geral das Colônias, Lisboa, 1945, volume II, págs. 167; Luís Mendonça de Albuquerque - o primeiro guia náutico português e o problema das latitudes na marinha dos séculos XV e XVI, in Revista da Universidade de Coimbra, volume 19, 1960, págs. 6-15 da separata. 
da não se sabia da existência do exemplar de Munique e já era conhecida uma coletânea muito semelhante encontrada na Biblioteca de Évora, designada vulgarmente por Regimento de Évora. Nela vemos também um regimento de navegação análogo ao do exemplar de Munique, mas redigido de maneira mais sucinta, a mesma tradução em língua portuguêsa do Tratado da Esfera de Sacrobosco, e no fim, a mesma tradução da carta de Munzer a D. João Il. Esta coletânea foi também publicada por Joaquim Bensaude, em Genebra, e também em Reproduction fac-similé du seul exemplaire connu appartenant à la Bibliothèque d'Évora (34). Foi impressa por German Galhardo em data posterior à do exemplar de Munique, e que bem pode ser 1516 ou 1517 (35). German Galhardo teria começado a trabalhar em Portugal após Hermão de Campos (36). O regimento de navegação inserto nesta coletânea é nitidamente posterior ao da coletânea de Munique. São estas as razões que nos levam a afirmar que a fonte de Duarte Pacheco Pereira deve ter sido a coletânea de Munique e não a de Evora. Certamente que não na edição correspondente ao único exemplar conhecido, mas seguramente numa edição anterior, ou então, poderemos ainda admiti-lo, na sua forma primitiva manuscrita.

2). - Dois passos do mesmo Prólogo do Livro I em que Duarte Pacheco Pereira se serviu certamente da mesma fonte, para nós desconhecida, de Rui de Pina em passos semelhantes da sua Crônica de $\mathbf{D}$. Afonso $\mathbf{V}$ (37) . No primeiro dêstes passos Duarte Pacheco Pereira escreve:

com muitas e grandes despesas de sua fazenda e mortes de criados seus, naturais Portugueses.

\footnotetext{
(34). - Joaquim Bensaude: Tractado da Spera do Mundo - Regimento da declinação do sol - Reproduction fac-similé du seul exemplaire connu appartenant à la Bibliothèque d'Evora, Genève, s. $d$.

(35). - Ver: Joaquim Bensaude - Regimento do Estrolabio e do Quadrante Tractado da Spera do Mundo, Munique, 1914, Introduction, pág. 8; Luciano Pereira da Silva - obras Completas, Agência Geral das Colônias, Lisboa, 1945, volume II, págs. 5, 193; Luís Mendonça de Albuquerque o primeiro guia náutico português e problema das latitudes na marinha dos séculos XV e XVI, in Revista da Universidade de Coimbra, volume 19, 1960, pág. 7 .

(36). - Antônio Joaquim Anselmo: Bibliografia das obras impressas em Portugal no século XVI, Lisboa, 1926, pág. 160.

(37). - Chronica do Senhor Rey $D$. Affonso $\mathbf{V}$ escrita por Ruy de Pina, chronista mór de Portugal, e Guarda mór da Torre do Tombo, in Coleção de Livros inéditos de História Portuguêsa... publicados por ordem da Academia Real das Sciencias de Lisboa por José Corrêa da Serra, Tomo I, Lisboa, 1790, págs. 486-489.
} 
Na Crônica de Rui de Pina vemos um passo sôbre o mesmo assunto em que os têrmos empregados são quase os mesmos:

e com inumeravees gastos de suas rendas e fazenda, nom receando infyndos trabalhos, mortes, e perigos de seus criados e servydores.

Neste mesmo texto do Esmeraldo de situ orbis Duarte Pacheco Pereira refere-se brevemente ao descobrimento e ao povoamento da ilha da Madeira:

mandou descobrir a ilha da Madeira e a mandou povoar.

Rui de Pina ainda no mesmo texto da sua Crônica não esquece também o descobrimento e o povoamento da ilha da Madeira:

mandou primeiramente navegar e descobrir pello mar Oceano, onde se acharam logo e povoraram as ricas e fertilles Ylhas da Madeira, que foram as primeiras que no mar Oceano estes Reinos tiveram.

3) . - Ainda um passo do mesmo Prólogo do Livro I em que Duarte Pacheco Pereira se inspirou nitidamente num texto que Rui de Pina (Crônica de D. Afonso V) (38) e João de Barros (Ásia) (39) também utilizaram. Ainda que a semelhança seja maior com o texto de João de Barros, o texto de Rui de Pina não provém certamente de fonte diferente. Esta fonte não foi ainda identificada, mas podemos desde já afirmar ter ela estreitas relações com a Bula de Six to IV, promulgada em 21 de junho de 1481 (40). Lemos no Esmeraldo de situ orbis:

e porque com mór fundamento e mais santamente esta empresa prosseguisse, ela lhe foi primeiro concedida pelos Santos Padres de Roma, s. pelo papa Eugénio quarto e Martinho quinto e. Sixto quarto, e assim pelos outros que despois destes vieram, aos quais aprouve que o dito Infante, com tôdolos Reis de Portugal que despois dele viessem por legítima sobcessão, houvessem para sempre dos ditos promontórios de Não e do Bosador em diante tôdalas mais ilhas, portos, tratos, resgates, pescarias e conquistas de toda Guiné, descobertas e por descobrir, em a ouriental e meridional plaga e Indios inclusivé, sob inu-

(38) - Didem.

(39). - Asía, Primeira Década, Livro I, Capítulo 7.

(40). - Ver a Bula de Sixto IV no Arquivo Nacional da Tôrre do Tombo, Bulas, maço 26, n.o 10 (Tradução da época em língua portuguêsa a seguir ao texto latino). 
merábeles excomunhões, defesas e enterditos, que outros alguns príncipes, senhorios, nem comunidades nas ditas partes e terras nem tocar possam, segundo se mais largamente contém em suas bulas e lêtaras que ao dito Infante e aos mesmos reis sobre este caso são concedidas, as quais estão na Torre do Tombo desta cidade de Lixboa.

$\mathrm{Na}$ Ásia de Joã̀o de Barros, vemos:

Depois o Papa Eugénio Quarto e o Papa Nicolau Quinto, té o Papa Sixto, a suplicação del-Rei Dom Afonso e del-Rei Dom João seu filho, concederam a eles e a seus sucessores, per suas bulas, doação perpétua de tudo o que descobrissem por este mar Oceano, demarcando do Cabo Bojador té a oriental plaga da India, inclusive, com tôdolos reinos, senhorios, terras, conquistas, portos, ilhas, tratos, resgates, pescarias, sob inumeráveis e graves excomunhões defesas e interditos que outros alguns reis, principes, senhorios, comunidades, não entrem nem possam entrar em as tais partes e mares adjacentes, segundo se mais largamente contém em suas bulas (42).

Ainda que a semelhança não seja tão nítida, o texto de Rui de Pina não deixa certamente de ter como origem a mesma fonte:

$E$ assy o dito Ifante como aconselhado e esforçado, já per divyna ynspiraçam movydo a ysso, com respeitos de magnanimo Princepe e muy Catolico Cristão, e como muy l'eal vassallo dos Reis e da Coroa de Portugal desejoso do acrecentamento, gloria, e louvor delles, sospirando pela santa honrrada e proveitosa conquista de Guiné, mandou logo pedir e suplicar ao Papa Martynho, quinto, na Igreja de Roma presidente, que em nome de Deos cujo poder tinha, concedesse e fizesse aa dita Coroa e herdeiros della pera sempre, como com acordo e aprovaçam do Sagrado Collegio dos Cardeaaes fez, e concedeo solene e perpetua doaçam, e the deu o senhorio proprio de todo o que na costa do dito mar Occeano, nos mares a ella ajacentes dos marcos e cabos de Nam e do Bojador contra o meo dia e oriente per elles e per seus sobcessores, e per suas jentes pellos tempos em diante se achasse e descobrisse atée os Indios inclusivamente. A qual doaçam e concessam do dito Papa Martynho, despois o Papa Eugenio, e o Papa Nycolláo, e o Papa Syxto aa suplicaçam d'El-Rey Dom

(42). - Tal como a carta de Munzer a D. João II nos permitiu corrigir no manuscrito-cópia do século XVIII um salto de palavras do copista, também êste texto de João de Barros nos permitiu corrigir três erros do mesmo copista: subre por sob; emditos por enterditos; villas por bulas. 


\begin{abstract}
Afonso, e d'El-Rey Dom Joam seu Fylho, confirmaram e aprovaram com sua graça e poder, com muitas graças e benções e liberdades aos Reis de Partugal presentes e futuros, que a prosseguissem, e com grandes excomunhões, graves Censuras e maldições a todollos Cristaañs, que em qualquer maneira sem prazer e consentimento dos ditos Reis de Portugal contra ellas fossem, como nas Bulas Apostolicas que se disso concederam mais perfeita e comprydamente se contém, as quaees sendo hum divino favor e verdadeiro e legitimo títullo, pera se a dita navegaçam descobrymento e conquista navegar e prosseguir, o dito Yfante logo prymeiramente com o santo e virtuoso principio de tam aventurado fym a emprendeo e prosseguio (43):
\end{abstract}

Estes textos de Duarte Pacheco Pereira, João de Barros, e Rui de Pina, tiveram certamente uma fonte comum que não foi, no entanto, nem a bula de Eugênio IV, citada pelos três, nem a de Martinho V, citada por Duarte Pacheco Pereira e Rui de Pina: nenhuma delas tem relação com os assuntos tratados nos textos em questão. Devem ter tido como fonte um texto certamente relacionado com a bula de Sixto IV, de 21 de junho de 1481, citada pelos três, e que confirma as de Nicolau V (1454) (citada por João de Barros e Rui de Pina) e Calixto III (1455) . A bula de Sixto IV não foi certamente a fonte direta, pois o texto desta bula não corresponde inteiramente aos textos de Duarte Pacheco Pereira, João de Barros e Rui de Pina. Por outro lado é notório que Duarte Pacheco Pereira não se sentia muito à vontade nestes assuntos, pois cita Eugênio IV antes de Martinho V. A cronologia mostra-nos que a ordem é completamente a inversa: Martinho V (1417-1431), Eugênio IV (1431-1447), Nicolau V (1447-1455), Calixto III (1455-1458), Pio II (1458-1464), Paulo II (1464-1471), Sixto IV (1471-1484). Terse-ia enganado o copista do texto do Esmeraldo de situ orbis, e teria escrito Martinho V por Nicolau V? Não nos parece, pois a admití-lo, seria necessário explicar porque é que nos aparece Eugênio IV, do qual nenhuma bula existe que se ocupe dos assuntos tratados no texto de Duarte Pacheco Pereira. Esta mesma observação poderemos fazer aos textos de João de Barros e Rui de Pina. Enfím, a fonte dos três deve ter sido a mesma, e deve ter relações, como já dissemos, com a bula de Sixto IV.

(43). - Este texto de Rui de Pina permitiu-nos corrigir dois erros do copista do manuscrito do Esmeraldo de situ orbis: as formas incompreensivels cobersam e cobasam, que corrigimos segundo êste texto em concessão. 
4). - Dois passos do texto do Esmeraldo de situ orbis, um ainda do Prólogo do Livro I, e outro do Capítulo 3 do Livro IV, assemelham-se a um texto de Valentim Fernandes na Epístola sobre a tralladaçam do livro de Marco Paulo (44), escrita alguns anos antes da obra de Duarte Pacheco Pereira, e impressa pelo próprio Válentim Fernandes em 1502. No Prólogo do Livro I, Duarte Pacheco Pereira diz:

E entre tôdolos príncipes oucidentais da Europa, Deos sòmente quiis escolher Vossa Alteza que este bem soubesse, e recebesse, e possuisse os tributos dos reis e príncipes bárbaros do ouriente, os quais Roma no tempo da sua prosperidade, quando mandava uma grande parte do orbe, nunca assi os pôde haver nem fazer trabutários, mas contrariando sempre sua sobgeição lhe mataram Marco Crasso, capitão muito esforçado, com vinte mil homens e dez mil cativos de seu exército; e agora por uma virtude divinal e graça especial, Vossa Alteza manda tudo, sendo o caminho de vossos cavaleiros posto tanto avante pelas terras e Indicos mares e Asiáticas ribeiras, como onde reluziram os feitos do grande Alexandre.

No passo do Capítulo 3 do Livro IV, lemos:

e quem bem considerar tamanhas cousas como estas, já muita parte dos famosos feitos d'Alixandre Maugno e dos Romanos ficam muito abaixo em respeito desta santa e grande conquista.

Num relativamente longo texto da Epístola citada, Valentim Fernandes faz considerações sempre à volta dêste mesmo assunto. Como exemplo, que não é mais significativo do que outros nesta mesma Epístola, vemos:

Onde fica Alexandre magno com seu capitam Onesecrito. Onde os virtuosos Romãos com o seu mandado que fizerom que nenhum passasse as colunas de Ercules pera que nom fossem priuados do titulo da sua monarchia. Passou vossa senhoria nom digo soomente toda a linea equinocçial mas ajnda aos vltimos fims de oç̧idente e começo de oriente ate as terras do gram cham onde ja começa de soar vosso poderoso nome.

No entanto, muitos textos semelhantes aos que acabamos de citar podem ver-se na vasta literatura ligada aos descobri-

\footnotetext{
(44). - Marco Paulo - o Livro de Nicolao Veneto - Carta de Jerônimo de Santo Estevam, conforme a impressāo de Valentim Fernandes, feita em Lisboa em 1502; com três fac-símilles, introdução e indices por Francisco Maria Esteves Pereira, Lisboa, 1922.
} 
mentos (45), sendo nós por isso levados a concluir que se trata de idéias e frases muito conhecidas e repetidas na época.

5) . - No final do Prólogo do Livro I Duarte Pacheco Pereira cita um texto de Virgílio, mas a tradução que dá do passo das Geórgicas (46) é de tal maneira livre que podemos e devemos duvidar que êle tenha conhecido diretamente a obra de Virǵ́lio. Lemos no texto do Esmeraldo de situ orbis:

poderemos por vós dizer o que disse Virgílio por César Agusto: "Tu és governador do grande mar e todos honram as tuas grandezas e a ti sirva a última Tile".

E' esta a única citação de Virgílio em todo o texto da obra "de Duarte Pacheco Pereira. E é esta mais uma razão para pensarmos que o autor do Esmeraldo de situ orbis não conheceu diretamente a obra de Virgílio, e ter-se-ia apropriado dêste passo das Geórgicas, ou em texto para nós desconhecido, ou até por ouvir dizer, dado que se trata de um passo certamente muito conhecido e divulgado. E' o seguinte, o texto latino das Geórgicas:

An deus immensi venias maris: ac tua nautae / Numina sola colant: tibi seruiat ultima tyle (47).

6). - Finalmente, vejamos um passo do Capítulo 22 do Livro I do Esmeraldo de situ orbis em que Duarte Pacheco Pereira transcreve as palavras do Infante D. Henrique a Gil Eanes a quando da passagem do Cabo Bojador:

e certamente cousa é pera reprender os cavaleiros, criados do Infante Dom Anrique, que ele mandou por capitães de seus navios descobrir este 'cabo do Bojador, e assi os mareantes que com eles iam, não ousarem passar além, porque doze anos continuadamente foram enviados cada ano pelo Infante a este descobrimento, e como eram

\footnotetext{
"45). - Ver sôbre êste assunto: Luís de Matos - L'Expansion Portugaise dans la Littérature Latine de la Renaissance (Thèse Sorbonne), Paris, s. d., pags. 35-41 do exemplar datllografado.

r46). - Edições da obra de Virgilio consultadas: Opera cum servii commentarils, Venetiis, 1487; Publil Virgllil Maronis opus, a Paulo Andelocenst exactissime emendatum, Parisiusque in vico Sorbonico quam tersissime impressum, finitur. Anno 1489. Paris; Georgica cum commento, Paris, 1492; Liber Georgicorum Virgilii, cum commento familiari, Lyon, 1493; Publii Virgilii Maronis opera, Argentinae, 1502; Géorgiques, Texte établi et traduit par E. de Saint-Denis, Paris, 1956 (Ed. "Les Belles' Lettres"). o passo citado corresponde no texto de Virgilto a I, 29-30.

447). - A partir do texto latino de Virgílo corrigimos no manuscrito do Esmeraldo de situ orbis dois erros do copista do século XVIII: guiza por sirva (segundo o latim seruiat), e Aylle por Tile (segundo o latim tyle).
} 
acerca do Bojador e achavam o fundo baixo, que em três. braças d'áugua estavam uma légua de terra, e espantando-se das grandes correntes, nenhum ousava de se alargar ao mar, e passar além deste pracel, e então se tornavam à costa de Berbéria e de Graada, onde andavam. d'armada para tomarem algumas presas com que forrassem a despesa d'armação; e por não passarem o dito cabo, - Infante recebia disto grande desprazer; e desejan-: do passar este cabo do Bojador e correr a costa adiante, no ano de Nosso Senhor de mil e quatrocentos e trinta e quatro anos o Infante mandou armar uma barca em que enviou por capitão um escudeiro seu criado, que se chamava Gilianes, ao qual falou nesta maneira: "Gilianes, vós sabeis como vos eu criei de moço pequeno e quanta confiança tenho em vós pera as cousas de meu servico, e por isso vos escolho entre tôdolos meus pera irdes por capitão desta barca descobrir e passar além o cabo do Bojador; e ainda que por esta viagem vós não façais mais que passardes o dito cabo, isso só terei por bem feito, e vós não podeis achar tamanho perigo que a esperança do galardão que vos eu darei não seja muito maior"; e disse mais o Infante: "em verdade eu não sei que imaginação foi esta que todos tomastes de cousa que não é nada; porque se isto que dizem tivesse alguma autoridade, por pouca que fosse, não vos daria tamanha culpa; mas querês-me dizer que por oupinião de quatro mareantes, os quais, como são tirados da carreira de Frandes ou d'outros portos onde costumam navegar, não sabem mais: o que fazem; porém vós ide todavia e não temais e passe-se o cabo além, que não podeis de lá trazer senão muita honra e proveito"; e estas palavras emprimiram tanto. no coração de Gilianes que, esquecendo todo o temor e movido de grande desejo para servir o Infante, ele no dito ano de quatrocentos e trinta e quatro anos passou além deste cabo do Bojador cinquenta léguas; e da vinda que veio, o Infante o fez cavaleiro, e o galardoou como devia, e com muita honra e fazenda o casou na vila de Lagos, onde viveo muitos anos, e este Gilianes foi o primeiro capitão que passou além do cabo do Bojador as ditas léguas, e portanto é razão fazer-se aqui memória dele.

No Capítulo IX da Crônica dos feitos de Guiné de Gomes. Eanes de Zurara, lemos sôbre êste mesmo assunto:

Com grande paciencia recebya sempre o iffante aquelles que assy envyava por capitães de seus navyos em busca. daquella terra, nom lhe mostrando algum reprendimento de sua mingua, ante com graciosa contenença, ouvya seus. aqueecimentos fazendo-lhe aquellas mercees que tiinha 
acostumado de fazer aos que o bem servyam; e ou aquelles, ou outros alguns speciaaes de sua casa, fazia logo tornar com seus navyos armados, acrecentando cada vez mais no encarrego, com prometimento de mayores gallardoões, se acrecentassem alguma cousa na vyagem que os primeiros fezerom, perque elle podesse cobrar algum conhecimento daquela duvyda. $E$ finalmente, despois de doze annos, fez o iffante armar huma barcha, da qual deu a capitanya a hum Gil Eannes, seu escudeiro, que ao despois fez cavalleyro, e agasalhou muy bem, o qual seguin. do a vyagem dos outros, tocado daquelle meesmo temor, nom chegou mais que a as ilhas de Canarya, donde trouxe certos cativos, com que se tornou pera o regno. E foe esto no anno de Jhu. Xpo de mil e quatro centos e trinta e trez. Mas logo no anno seguinte, o iffante fez armar outra vez a dicta barcha, e chamando Gil Eannes a departe, o encarregou muyto que todavya se trabalhasse de passar aquelle cabo, e que ainda que por aquella vyagem mais nom fezesse, aquello terya por assaz. Vós nom podees, disse o iffante achar tamanho perigoo, que a esperança do gallardom nom seja muyto mayor; e em verdade eu me maravilho, que maginaçom foe aquesta que todos filhaaes de huma cousa de tam pequena certidom, ca se ainda estas cousas que se dizem tevessem alguma autoridade, por pouca que fosse, nom vos darya tamanha culpa, mas quereesme dizer que por openyom de quatro mareantes, os quaees como som tirados da carreira de Frandes, ou de alguns outros portos pera que comumente nave. gam, nom sabem mais teer agulha nem carta pera marear; porem vos hii todavya, e nom temaaes sua openyam, lazendo vossa vyagem, ca com a graça de Deos, nom poderees della trazer se nom honra e proveito. O iffante era homem de muy grande autoridade, polla qual suas amoestaçoões, por brandas que fossem, eram pera os sesudos de muy grande encarrego, como se mostrou per obra em aqueste, que despois destas pallavras, determinou em sua voontade nom tornar mais ante a presença de seu senhor, sem certo recado daquello por que o envyava; como de feito fez, ca daquella vyagem, menospreçando todo perigoo, dobrou o cabo a allem, onde achou as cousas muyto pello contrairo do que elle e os outros ataally presumyram. E ja seja que o feito, quanto aa obra, fosse pequeno, soo pello atrevimento foe contado por grande, ca se o primeiro que chegou acerca daquelle cabo, fezera outro tanto, nom lhe fora tam louvado, nem agradecido, mas quanto o perigoo da cousa aos outros foe posto em mayor temor, tanto trouxe mayor honra ao cometimento daqueste. Se o acontecimento de Gil Eannes, entrinsicamente lhe apresentava alguma glorya, bem deve seer conhecido pellas pal- 
lavras que the 0 iffante disse ante de sua partida, cuja: certa speryencia foe assaz manifesta ao tempo de sua chegada, ca foe delle muy bem recebido, nom sem proveitoso acrecentamento na honra e fazenda. E entom the contou todo o caso como passara, dizendo como fezera lançar. o batel fora, no qual sayra em terra, onde nom achara. gente alguma, nem sinal de povoraçom. $E$ porque, senhor, disse Gil Eannes, me pareceo que devia trazer algum sinal de terra, pois que em ella sahya, apanhey estas hervas. que aquy apresento aa vossa mercee, as quaaes nós em. este regno chamamos rosas de sancta Marya. E acabado. assy o recontamento de sua vyagem, fez o iffante armarhum barinel, no qual mandou Affonso Gançalvez Baldaya que era seu copeiro, e assy Gil Eannes com sua barcha, mandando que tornassem la outra vez, como defeito fezerom, e passarom a allem do cabo cinquoenta legoas, onde acharom terra sem casas, e rastro dhomens e de camellos. $E$ ou por lhe seer assy mandado, ou por necessydade, tornarom com este recado, sem fazendo outra cousa que. de contar seja (48).

Léon Bourdon na sua tradução crítica e comentada da: Crônica dos feitos de Guiné (49) de Gomes Eanes de Zurara,. dá-nos o estado atual desta questão:

"les points de contact entre l'Esmeraldo et la Chronique de Zurara se réduisent à ce court passage, et presquepartout ailleurs ils diffèrent très sensiblement l'un de l'autre. Si donc Duarte Pacheco a bien consulté une oeuvre. contenant le discours de l'Infant, cette oeuvre n'était certainement pas la Chronique de Zurara, et le manuscrit en. question n'avait par conséquent aucun rapport avec le manuscrit de Paris". "V. Magalhães Godinho (50) émet l'hypothèse que Zurara et Pacheco ont pu s'appuyer sur unesource commune qui ne nous est pas parvenue, par exemple la chronique d'Afonso Cerveira. Si cette hypothèse. se vérifiait, nous disposerions ainsi d'un élément nous. permettant de juger des retouches de style apportées par Zurara à Cerveira. Mais on a vu... que la source utilisée. par Pacheco diffère par ailleurs très sensiblement de Zurara, et donc de Cerveira".

Finalmente, somos levados a pensar que se trata de uma: fonte até agora desconhecida, e na qual se inspiraram provà-

(48). - Gomes Eanes de Zurara: Crônica dos feitos de Guiné, edição da Agéncia. Geral das Colônias, Lisboa, 1949.

(49). - Chronique de Guinée, Dakar, 1960, Introduction, pág. 18, n. 2, e Chapitre IX, pág. 72, n. 1 ,

(50). - Documentos sôbre a Expansão Portuguêsa, Lisboa, 1943, volume I, pá. 231 , n. 5 . 
velmente Afonso Cerveira e Duarte Pacheco Pereira, ou mais provàvelmente ainda Gomes Eanes de Zurara e Duarte Pacheco Pereira.

À margem do livro de história, lembremos um passo do Capítulo 7 do Livro III, em que Duarte Pacheco Pereira fala dos gatos meimões que designa também pelo nome de babois:

gatos meimões, a que chamam babois, quase tão grandes como homens, os quais têm tão grandes barbas, que o não poderá crer senão quem os vir.

Este passo levou-nos a pensar em passo semelhante do Manuscrito Valentim Fernandes (51), onde lemos:

e muytos gatos meymões, baboynos de muitas sortes, algalia e gatos dalgalia (52).

Se aproximarmos êstes dois textos, poderemos por-nos a hipótese de que Duarte Pacheco Pereira e Valentim Fernandes tiveram à disposição a mesma fonte, para nós desconhecida. Duarte Pacheco Pereira deve ter, no entanto, compreendido mal o texto original: é bastante provável que os babois de Duarte Pacheco Pereira não sejam os gatos meimões, mas sim os babuínos, os baboynos de Valentim Fernandes. Isto é tanto mais provável quanto êle faz alusão às suas grandes barbas, e à sua grande estatura. Não se pode excluir a hipótese de que êle se refira também aos gatos meimões, mas atribuindo-lhe características próprias aos babuímos.

Se encararmos agora o Esmeraldo de situ orbis como um roteiro, não é menos difícil descobrir as fontes para êste as-

(51). - O Manuscrito Valentim Fernandes, Academia Portuguêsa da História, Lisboa, 1940, pág. 75 .

(52). - Na Description de la Côte Occidentale d'Afrique (Sénégal au Cap de Monte, Archipels) par Valentim Fernandes (1506-1510), edição de Th. Monod, A. Teixeira da Mota e R. Mauny, Bissau, 1951, p. 157, podemos ler a propósito dos gatos meimões (nota 78): "Un lémurien, sans doute un Galago". No Dictionnaire des Sciences Théoriques et Appliquées de Privat-Deschanel e A. Focillon, Paris, 1883, 2a. Parte, lemos: "Lémuriens (Zoologie). Lemurida, Gray-Famille de l'ordre des Quadrumanes, établie par Et. Geoffroy; correspondant au grand genre Lemur de Lin. et Maki de Cuv. Vulgairement nommé Faux-Singe, à cause de plusleurs traits de ressemblance avec les singes; ils ont pour caractères: les quatre pouces bien développés et opposables, et le premier doigt de derrière armé d'un ongle pointu et relevé; tous les autres ongles plats; pelage laineaux; les dents commencent à avoir de petits tubercules aigus, comme dans les Insectivores. Genres principaux: Maki propre, Iudri, Loris, Galago, Tarsier. - George H. T. Kimble na sua traduçäo crítica da obra de Duarte Pacheco Pereira ("Esmeraldo de situ orbis" by Duarte Pacheco Pereira, Londres, 1937) cita sôbre êste assunto: W. L. Sclater - The Mammals of South Africa, vol. I, págs. 34-38. Os baboynos de 
pecto da obra de Duarte Pacheco Pereira. O único roteiro conhecido anterior ao Esmeraldo de situ orbis é aquêle que habitualmente designamos por Livro de Rotear (53), de autor anônimo e inserto no Manuscrito Valentim Fernandes. Podemos pensar que neste domínio Duarte Pacheco Pereira se serviu de numerosos roteiros da época de que não nos resta infelizmente senão o Livro de Rotear, e também e sobretudo da sua experiência pessoal de navegador numa costa que êle deve ter percorrido muitas vêzes.

No que diz respeito ao Esmeraldo de situ orbis considerado como regimento de navegação, conhecemos apenas duas obras que lhe poderão ser anteriores: o célebre Regimento de Munique, de que, como já vimos, uma ou várias edições foram impressas antes que Duarte Pacheco Pereira tivesse redigido o seu Esmeraldo de situ orbis, e o não menos conhecido Regimento de Evora, se admitirmos - o que nos parece bastante provável - que êle remonta a uma data muito anterior à da sua impressão por German Galhardo. De qualquer modo, neste domínio a contribuição de Duarte Pacheco Pereira marca progressos tão consideráveis que o mais provável é que êle tenha feito obra original, o que não exclui a existência de uma tradição anterior de que os Regimentos citados são os únicos testemunhos até nós chegados.

(Continua).

JOAQUIM BARRADAS DE CARVALHO

Professor de Histórla Ibérica da Faculdade de Fllosofia, Ciências e Letras da Universidade de São Paulo.

que fala Valentim Fernandes são os babuinos. No Dictionaire des Sciences Théoriques et Appliquées acima citado, lemos: "Babouin (ZOoIogie), Simia cynocephalus, Cuv. - Genre de Quadrumane, famille des Singes, sous-genre des Singes propement dits ou singes de l'Ancient Continent. Ils sont caractérisés par cinq tubercules aux dernières molaires, les fesses calleuses, des abajoues, museau allongé et comme tronqué au bout; queue d'une longueur médiocre, pelage verdâtre, touffes des joues blanchâtres, visage couleur de chair; plusieurs naturalistes ont confondu le Babouin avec le Papiou (Simia sphinx, Lin.), dont il diffère cependant en ce que celui-ci a le visage noir, la queue longue, les touffes des joues fauves. En général les uns et les autres sont des singes d'assez grande taille, effrayants par leur férocité. Is vivent en Afrique, surtout en Guinée". O Dicionário de F. J. Caldas Aulete, dá: "Babuíno: cynocephalo habitante da Guiné (Simia cynocephalus)".

(53). - Pequena coletânea de roteiros, anteriores a 1500, e com os títulos: Este liuro he de rotear .s. de todo Portugal e de Galiza atee Sorlinga e Oexamte e das ylhas de Madeyra e dos Açores e de Guynee e começa de fallar de como jaz a Berlenga cõ ho cabo de Fijsterra, Ho liuro das Rotas do Castello de Sam Jorge, Aqui falla da rota do Cabo Fremoso pera ylha de Samtamtoneo, Do Ryo Grăde. 